Published on Web 08/19/2004

\title{
Understanding the Role of Sodium during Adsorption: A Force Field for Alkanes in Sodium-Exchanged Faujasites
}

\author{
Sofía Calero, ${ }^{*,+, \ddagger}$ David Dubbeldam, ${ }^{\dagger}$ Rajamani Krishna, ${ }^{\dagger}{\text { Berend Smit }{ }^{\dagger}}^{\dagger}$ \\ Thijs J. H. Vlugt, ${ }^{\S}$ Joeri F. M. Denayer,,$"$ Johan A. Martens, ${ }^{\perp}$ and \\ Theo L. M. Maesen\# \\ Contribution from the Department of Chemical Engineering, University of Amsterdam, Nieuwe \\ Achtergracht 166, 1018 WV Amsterdam, The Netherlands, Condensed Matter and Interfaces, \\ Debye Institute, Utrecht University, P.O. Box 80.0003508 TA Utrecht, The Netherlands, Dienst \\ Chemische Ingenieurstechniek, Vrije Universiteit Brussel, Pleinlaan 2, B-1050 Brussel, Belgium, \\ Centrum voor Oppervlaktechemie en Katalyse, Katholieke Universiteit Leuven, Kasteelpark \\ Arenberg 23, B-3001 Leuven, Belgium, and ChevronTexaco, Energy Technology Company, \\ 100 Chevron Way, Richmond, California 94802-0627
}

Received April 26, 2004; E-mail: scaldia@dex.upo.es

\begin{abstract}
We have developed a united atom force field able to accurately describe the adsorption properties of linear alkanes in the sodium form of FAU-type zeolites. This force field successfully reproduces experimental adsorption properties of $n$-alkanes over a wide range of sodium cation densities, temperatures, and pressures. The force field reproduces the sodium positions in dehydrated FAU-type zeolites known from crystallography, and it predicts how the sodium cations redistribute when $n$-alkanes adsorb. The cations in the sodalite cages are significantly more sensitive to the $n$-alkane loading than those in the supercages. We provide a simple expression that adequately describes the $n$-alkane Henry coefficient and adsorption enthalpy as a function of sodium density and temperature at low coverage. This expression affords an adequate substitute for complex configurational-bias Monte Carlo simulations. The applicability of the force field is by no means limited to low pressure and pure adsorbates, for it also successfully reproduces the adsorption from binary mixtures at high pressure.
\end{abstract}

\section{Introduction}

Research activity on zeolites, and on adsorption and heterogeneous catalysis in general, has experienced increased interest in the past few years. ${ }^{1-4}$ Zeolitic materials have outstanding properties due to their regular structures and high internal surface areas, and they are used in industry as ion exchangers, catalysts, and adsorbents. ${ }^{5,6}$ Molecular simulations are a powerful tool for gaining insight into these industrial processes at a molecular level. With the decreasing cost of computer simulations, there is an increasing demand for the use of detailed simulations to predict the properties resulting from the interaction of molecules and zeolites.

\footnotetext{
$\dagger$ University of Amsterdam.

$\div$ Current address: Department of Experimental Sciences, University Pablo de Olavide, Ctra. Utrera km 1, 41013 Sevilla, Spain.

$\S$ Utrecht University.

"Vrije Universiteit Brussel.

${ }^{\perp}$ Katholieke Universiteit Leuven.

\# ChevronTexaco.

(1) Barthomeuf, D. Catal. Rev.-Sci. Eng. 1996, 38, 521-612.

(2) Hattori, H. Chem. Rev. 1995, 95, 537-558.

(3) Sanchez-Sanchez, M.; Blasco, T. J. Am. Chem. Soc. 2002, 124, $3443-$ 3456.

(4) Concepcion-Heydorn, P.; Jia, C.; Herein, D.; Pfander, N.; Karge, H. G.; Jentoft, F. C. J. Mol. Catal. 2000, 162, 227-246.

(5) Schenk, M.; Calero, S.; Maesen, T. L. M.; van Benthem, L. L.; Verbeek, M. G.; Smit, B. Angew. Chem., Int. Ed. 2002, 41, 2499-2502.

(6) Schenk, M.; Smit, B.; Vlugt, T. J. H.; Maesen, T. L. M. Angew. Chem., Int. Ed. 2001, 40, 736-739.
}

10.1021/ja0476056 CCC: $\$ 27.50$ @ 2004 American Chemical Society
FAU-type zeolites are the most widely used zeolites in catalysis and separation processes. ${ }^{2,7-9}$ In their synthesized form, the composition of the unit cell is $\mathrm{Na}_{x} \mathrm{Al}_{x} \mathrm{Si}_{192-x} \mathrm{O}_{384}$, where 96 $\geq x \geq 0$. FAU-type zeolites have been labeled either $\mathrm{X}$ or $\mathrm{Y}$ depending on their framework aluminum density $(x)$. Zeolite $\mathrm{X}$ has a framework aluminum density between 96 and 77 aluminum atoms per unit cell, whereas zeolite Y contains fewer than 77 framework aluminum atoms per unit cell. The FAUtype pore structure consists of sodalite cages arranged in 1.2$\mathrm{nm}$ wide supercages accessible through 0.72 -nm windows. Since the sodalite cages are not readily accessible for alkanes, adsorption tends to be limited to the supercages.

The adsorption properties of FAU-type zeolites containing framework aluminum and sodium cations depend on the interaction of the zeolite framework and the non-framework cations with the adsorbate molecules. Therefore, a thorough characterization involving all interactions between these elements (zeolite framework, adsorbates, and non-framework cations) is a missing key ingredient for understanding their performance as adsorbents.

A variety of computational studies have been reported on the location of cations in adsorbate-free faujasites. ${ }^{10-18}$ Most of these studies used force fields with the same partial charge

(7) Satterfield, C. N.; Cheng, C. S. AIChE J. 1972, 18, 720-723.

(8) Breck, D. W. Zeolite Molecular Sieves; Wiley: New York, 1974. 
on silicon and aluminum. However, because of the close proximity between cations and framework atoms this approach is unsuited for modeling cations in zeolites and it cannot account for the allocation of cations to specific positions. ${ }^{11,13,14,17-19}$ Simulations with force fields distinguishing aluminum from silicon have also been performed, but these were mostly limited to zeolites with alternating silicon and aluminum to minimize the number of different types of bridging oxygen atoms. ${ }^{11,20}$ More importantly, these simulations completely ignored cation mobility. ${ }^{11}$ Not until the publication of a force field by Auerbach et al. ${ }^{14}$ in 1999 were these constraints overcome.

Computer simulation studies on the adsorption of molecules in cation-free FAU-type silica have also been reported. ${ }^{21}$ There are a few simulations on the adsorption behavior of hydrocarbons in the sodium form of FAU-type zeolites ("Na-FAU") focusing on halocarbons ${ }^{12,22-25}$ and aromatics. ${ }^{26,27}$ There are hardly any simulations involving linear alkanes on Na-FAU except for a few studies on the adsorption of the smallest, and computationally least expensive, hydrocarbons: methane ${ }^{28-32}$ and ethane. ${ }^{33}$ In 1978, Bezus et al. ${ }^{28}$ used an atomistic representation in Monte Carlo simulations of methane in zeolite $\mathrm{NaX}$. A decade later, Yashonath et al. ${ }^{34}$ reported the first Monte Carlo study of the adsorption of a single methane molecule in $\mathrm{NaY}$, and Woods and Rowlinson ${ }^{29}$ computed the adsorption isotherms and isosteric heats of adsorption of methane in $\mathrm{NaX}$ and $\mathrm{NaY}$ using Grand Canonical Monte Carlo (GCMC) simulations. In both cases, the Kiselev potential model was used ${ }^{35}$ where interactions between methane and the atoms of the

(9) Denayer, J. F. M.; Ocakoglu, R. A.; Huybrechts, W.; Dejonckheere, B.; Jacobs, P.; Calero, S.; Krishna, R.; Smit, B.; Baron, G. V.; Martens, J. A. J. Catal. 2003, 220, 66-73.

(10) Smirnov, K. S.; Lemarie, M.; Bremard, C.; Bougeard, D. Chem. Phys. 1994 $179,445-454$.

(11) Vitale, G.; Mellot, C. F.; Bull, L. M.; Cheetham, A. K. J. Phys. Chem. B 1997, 101, 4559-4564.

(12) Mellot, C. F.; Davidson, A. M.; Eckert, J.; Cheetham, A. K. J. Phys. Chem. $B$ 1998, 102, 2530-2535.

(13) Auerbach, S. M.; Bull, L. M.; Henson, N. J.; Metiu, H. I.; Cheetham, A. K. J. Phys. Chem. 1996, 100, 5923-5930.

(14) Jaramillo, E.; Auerbach, S. M. J. Phys. Chem. B 1999, 103, 9589-9594.

(15) Ciraolo, M. F.; Norby, P.; Hanson, J. C.; Corbin, D. R.; Grey, C. P. J. Phys. Chem. B 1999, 103, 346-356.

(16) Krause, K.; Geidel, E.; Kindler, J.; Forster, H.; Smirnov, K. S. Vib. Spectrosc. 1996, 12, 45-52.

(17) Schrimpf, G.; Schlenkrich, M.; Brickmann, J.; Bopp, P. J. Phys. Chem. 1992, 96, 7404-7410

(18) Engelhardt, G. Microporous Mater. 1997, 12, 369-373.

(19) Olson, D. H. Zeolites 1995, 15, 439-443.

(20) Blake, N. P.; Weakliem, P. C.; Metiu, H. J. Phys. Chem. B 1998, 102, 67-74.

(21) Fuchs, A. H.; Cheetham, A. K. J. Phys. Chem. B 2001, 105, 7375-7383.

(22) Mellot, C. F.; Cheetham, A. K.; Harms, S.; Savitz, S.; Gorte, R. J.; Myers, A. L. J. Am. Chem. Soc. 1998, 120, 5788-5792.

(23) Mellot, C. F.; Cheetham, A. K.; Harms, S.; Savitz, S.; Gorte, R. J.; Myers, A. L. Langmuir 1998, 14, 6728-6733.

(24) Jaramillo, E.; Grey, C. P.; Auerbach, S. M. J. Phys. Chem. B 2001, 105, 12319-12329.

(25) Mellot, C. F.; Cheetham, A. K. J. Phys. Chem. B 1999, 103, 3864-3868.

(26) Gener, I.; Buntinx, G.; Bremard, C. Microporous Mesoporous Mater. 2000 $41,253-268$.

(27) Lachet, V.; Boutin, A.; Tavitian, B.; Fuchs, A. H. Faraday Discuss. 1997, 307-323

(28) Bezus, A. G.; Kiselev, A. V.; Lopatkin, A. A.; Pham, Q. D. J. Chem. Soc., Faraday Trans. 2 1978, 74, 367-369.

(29) Woods, G. B.; Rowlinson, J. S. J. Chem. Soc., Faraday Trans. 2 1989, 85, 765-781.

(30) Ghorai, P. K.; Sluiter, M.; Yashonath, S.; Kawazoe, Y. J. Am. Chem. Soc. 2003, 125, 16192-16193.

(31) Pellenq, R. J. M.; Tavitian, B.; Espinat, D.; Fuchs, A. H. Langmuir 1996, $12,4768-4783$

(32) Yashonath, S.; Demontis, P.; Klein, M. L. J. Phys. Chem. 1991, 95, 58815889.

(33) Henson, N. J.; Eckert, J.; Hay, P. J.; Redondo, A. Chem. Phys. 2000, 261, 111-124

(34) Yashonath, S.; Thomas, J. M.; Nowak, A. K.; Cheetham, A. K. Nature 1988, 331, 601-604.

(35) Kiselev, A. V.; Lopatkin, A. A.; Shulga, A. A. Zeolites 1985, 5, 261-267. framework were modeled in terms of a short-range LennardJones potential and a long-range Coulombic term. It is important to note that these simulations treated sodium cations as immobile and do not establish distinctions between silicon and aluminum and therefore cannot correctly allocate specific cation positions.

More recently, Maddox and Rowlinson ${ }^{36}$ have studied the adsorption of nitrogen and methane mixtures in $\mathrm{NaX}$ using the GCMC technique. As before, sodium cations were considered as an immobile part of the zeolitic framework and the interactions with the adsorbates were defined through the Kiselev potential model. Later studies increased the complexity of the potential model, obtaining relatively good agreement with experimental adsorption data for methane. ${ }^{31}$ Adsorption of ethane in $\mathrm{NaY}$ has been studied by Henson et al. using both inelastic neutron scattering and ab inito calculations. ${ }^{33}$ They used the same set of parameters as Mellot et al. ${ }^{12}$ in their simulations of chloroform in NaY. Finally, Yashonath et al. have also performed simulations of propane, ${ }^{37,38} n$-butane, ${ }^{39}$ and several $n$-alkanes ${ }^{40}$ in NaY but again discounting sodium mobility.

In this article, we present a force field where the nature, density, and mobility of the non-framework cation, the density of the framework aluminum, and all host-guest interactions are carefully taking into account. In section II, we explain the general computational methodology, the choice of our model, and the parameter optimization strategy. We also report a complete validation of the force field, as it accurately reproduces the sodium cation locations in adsorbate-free zeolites and the adsorption isotherms of $n$-alkanes (from methane to $n$-decane) in Na-FAU. In section III, we analyze the applications of this force field. We (1) address the question of cation location during adsorption, subsequently we (2) simplify the results with an empirical expression for Henry coefficients and heats of adsorption as a function of the sodium concentration, temperature, and linear alkane, and finally, we (3) extend our calculations to mixtures of alkanes at high pressure. In section IV, we give some concluding remarks.

\section{Methodology}

The development of our force field required (1) a model for the framework structure, (2) the partial charges of the zeolite atoms, (3) the interatomic potentials, and (4) an unambiguous optimization of potential parameters using configurational-bias Monte Carlo (CBMC) simulations. The conventional simulation techniques to compute adsorption isotherms are prohibitively expensive for long alkanes, whereas the CBMC technique simulates them at affordable cost. ${ }^{41}$ In a CBMC simulation, molecules are grown bead by bead, biasing the growth process toward energetically favorable configurations and avoiding overlap with the zeolite. During the growth, the Rosenbluth factor is calculated. The average Rosenbluth factor is directly related to the free energy and the Henry coefficient. ${ }^{42,43}$

Simulations were performed in cycles, and in each cycle one move was chosen at random with a fixed probability of performing a molecule

(36) Maddox, M. W.; Rowlinson, J. S. J. Chem. Soc., Faraday Trans. 1993, $89,3619-3621$

(37) Sayeed, A.; Mitra, S.; Kumar, A. V. A.; Mukhopadhyay, R.; Yashonath, S.; Chaplot, S. L. J. Phys. Chem. B 2003, 107, 527-533.

(38) Mukhopadhyay, R.; Sayeed, A.; Rao, M. N.; Anilkumar, A. V.; Mitra, S.; Yashonath, S.; Chaplot, S. L. Chem. Phys. 2003, 292, 217-222.

(39) Bandyopadhyay, S.; Yashonath, S. J. Chem. Phys. 1996, 105, 7223-7226.

(40) Rajappa, C.; Bandyopadhyay, S.; Subramanian, Y. Bull. Mater. Sci. 1997 20, 845-878.

(41) Smit, B.; Maesen, T. Nature 1995, 374, 42-44

(42) Frenkel, D.; Smit, B. Understanding Molecular Simulations: From Algorithms to Applications, 2nd ed.; Academic Press: San Diego, CA, 2002

(43) Dubbeldam, D.; Calero, S.; Maesen, T. L. M.; Smit, B. Phys. Rev. Lett. 2003, 90, Art. No. 245901. 
Table 1. Lennard-Jones Force Field Parameters in $\mathrm{Na}^{+}$Faujasites ${ }^{a}$

\begin{tabular}{|c|c|c|c|c|c|c|}
\hline & $\mathrm{O}_{A l}$ & $\mathrm{O}_{\mathrm{si}}$ & $\mathrm{Na}$ & $\mathrm{CH}_{4}$ & $\mathrm{CH}_{3}$ & $\mathrm{CH}_{2}$ \\
\hline \multirow{2}{*}{$\mathrm{CH}_{4}$} & 3.47 & 3.47 & 2.72 & 3.72 & 3.74 & 3.84 \\
\hline & 115 & 115 & 582.17 & 158.5 & 130.84 & 94.21 \\
\hline \multirow[b]{2}{*}{$\mathrm{CH}_{3}$} & 3.48 & 3.48 & 2.65 & 3.74 & 3.76 & 3.86 \\
\hline & 93 & 93 & 443.73 & 130.84 & 108 & 77.7 \\
\hline \multirow{2}{*}{$\mathrm{CH}_{2}$} & 3.58 & 3.58 & 2.95 & 3.84 & 3.86 & 3.96 \\
\hline & 60.5 & 60.5 & 310 & 94.21 & 77.7 & 56.0 \\
\hline \multirow{2}{*}{$\mathrm{Na}$} & 3.4 & 3.4 & 2.16 & 2.72 & 2.65 & 2.95 \\
\hline & 23 & 23 & 124.4 & 582.17 & 443.73 & 310 \\
\hline charge & \multicolumn{2}{|c|}{$\mathrm{O}_{\mathrm{Al}}$} & $\mathrm{O}_{\mathrm{Si}}$ & $\mathrm{Na}$ & $\mathrm{Si}$ & $\mathrm{Al}$ \\
\hline$q(\mathrm{e})$ & & & & +1.00 & +2.05 & +1.75 \\
\hline bond & \multicolumn{3}{|c|}{$U^{\text {bond }}=1 / 2 k_{1}\left(r-r_{0}\right)^{2}$} & & & \\
\hline \multirow[t]{2}{*}{ bend } & \multicolumn{3}{|c|}{$\begin{array}{l}k_{1} / k_{\mathrm{B}}=96500 \mathrm{~K} / \AA^{2}, r_{0}=1.54 \AA \\
U^{\text {bend }}=1 / 2 k_{2}\left(\cos \theta-\cos \theta_{0}\right)^{2}\end{array}$} & & & \\
\hline & \multicolumn{3}{|c|}{$k_{2} / k_{\mathrm{B}}=62500 \mathrm{~K}, \theta_{0}=114^{\circ}$} & & & \\
\hline torsion & \multicolumn{3}{|c|}{$U^{\mathrm{torsion}}=\sum^{5} \eta_{n} \cos ^{n} \phi, \eta_{n} / k_{\mathrm{B}}$ in $\mathrm{K}$} & & & \\
\hline
\end{tabular}

\begin{tabular}{cccccc}
\hline$\eta_{0}$ & $\eta_{1}$ & $\eta_{2}$ & $\eta_{3}$ & $\eta_{4}$ & $\eta_{5}$ \\
\hline 1204.654 & 1947.740 & -357.854 & -1944.666 & 715.690 & -1565.572 \\
\hline
\end{tabular}

${ }^{a} \sigma[\AA]$ value is the top entry; $\epsilon / k_{\mathrm{B}}[\mathrm{K}]$ is the bottom entry. The partial charges [e] of the framework and the sodium cations are given at the lower part of the table. $\mathrm{O}_{\mathrm{Al}}$ are oxygens bridging one silicon and one aluminum atom, and $\mathrm{O}_{\mathrm{Si}}$ are oxygens bridging two silicon atoms. The bond and bend parameters, the torsion potential, and the $\mathrm{O}-\mathrm{CH}_{x}$ interactions are taken from our previous works. ${ }^{58,59}$

displacement $(0.15)$, rotation around the center of mass $(0.15)$, exchange with the reservoir $(0.55)$, and partial regrowth of a molecule $(0.15)$. For mixtures, we included an exchange of the type of molecules $(0.05)$ and an exchange with the reservoir (0.5). The maximum translational and rotational displacements were adjusted to achieve an acceptance probability of $50 \%$. The total number of cations remained constant during simulations so only translation movements and regrowth at a random position in the zeolite were considered for this type of particles. The regrowing at a new, randomly selected position bypassed energy barriers.

Henry coefficients were computed in the NVT ensemble (at a fixed number of particles $\mathrm{N}$, volume $\mathrm{V}$, and temperature $\mathrm{T}$ ), including translation (0.1), rotation (0.1), partial regrowths $(0.1)$, and regrowths of the entire molecule (0.7). For the NVT simulations, the total number of cycles was at least $1 \times 10^{7}$. For the grand-canonical simulations, the number of cycles for one-component isotherms was $2 \times 10^{7}$ and at least $3 \times 10^{7}$ for the mixtures. More details on this simulation technique can be found elsewhere. ${ }^{42,44,45}$

A. Model. The FAU-type framework was built from silicon, aluminum, and oxygen utilizing the crystallographic positions of these atoms in dehydrated $\mathrm{NaX} .{ }^{19}$ Zeolites structures with lower framework aluminum densities were obtained by randomly substituting aluminum by silicon. This procedure automatically satisfies the Löwenstein rule and it should afford a reasonable approximation of the framework aluminum distributions obtained by experimental methods. ${ }^{46-49}$ The charge distribution on the oxygen framework was considered static; i.e., polarization of oxygen by nearby sodium cations was neglected. Our model explicitly distinguishes silicon from aluminum with a difference of $0.3 \mathrm{e}^{-}$between $q_{\mathrm{Si}}$ and $q_{\mathrm{Al}} .{ }^{14}$ Different charges were used for oxygen atoms bridging two silicon atoms, $q_{\mathrm{OS}}$, and oxygen atoms bridging one silicon and one aluminum atom, $q_{\mathrm{OAl}} . q_{\mathrm{OSi}}$ was obtained using the relation $q_{\mathrm{Si}}+\left(2 \times q_{\mathrm{OSi}}\right)=0$, making the zeolite neutral in the absence of aluminum, while $q_{\mathrm{OAI}}$ was chosen to make the total system charge equal to zero. ${ }^{50,51}$ All partial charges are listed in Table 1.

(44) Vlugt, T. J. H.; Krishna, R.; Smit, B. J. Phys. Chem. B 1999, 103, 11021118

(45) Smit, B.; Siepmann, J. I. J. Phys. Chem. 1994, 98, 8442-8452.

(46) Melchior, M. T.; Vaughan, D. E. W.; Jacobson, A. J. J. Am. Chem. Soc. 1982, 104, 4859-4864.

(47) Herrero, C. P. J. Chem. Soc., Faraday Trans. 1991, 87, 2837-2841.

(48) Vega, A. J. J. Phys. Chem. 1996, 100, 833-836.

(49) Peterson, B. K. J. Phys. Chem. B 1999, 103, 3145-3150.
The non-framework sodium cation density was adjusted to match the framework aluminum density, and the density of the zeolites was determined by the framework atoms (aluminum, silicon, and oxygen) and the non-framework cations (sodium). In our model, the sodium cations could move freely and adjust their position depending on their interactions with the framework atoms, other sodium cations, and alkane molecules. To sample cation motions, we used displacements and insertions at new randomly selected positions. These random insertions bypassed energy barriers.

Molecular simulations using flexible zeolites showed that a flexible lattice can potentially influence diffusion properties. ${ }^{52}$ To diffuse inside a zeolite the molecules had to pass energy barriers posed by channels and intersections. In a flexible zeolite framework, fluctuations can affect the size of the channels and intersections and, thereby, the height of these energy barriers. However, our study focuses on the low-energy, equilibrium configurations, so that the fluctuations in the higher-energy configurations in flexible zeolite models are negligible. ${ }^{53}$

The interactions between guest molecules (alkanes and sodium cations) with the zeolite host framework were modeled by LennardJones and Coulombic potentials. The Coulombic interactions in the system were calculated using the Ewald summation. ${ }^{42}$ The alkanes were described with a united atom model, in which $\mathrm{CH}_{x}$ groups were considered as a single interaction centers with their own effective potentials. ${ }^{54}$ The beads in the chain were connected by harmonic bonding potentials. The bond bending between three neighboring beads was modeled by a harmonic cosine bending potential, and changes in the torsional angle were controlled by a Ryckaert-Bellemans potential. The beads in a chain separated by more than three bonds interacted with each other through a Lennard-Jones potential. The interactions of the adsorbed molecules with the zeolite were dominated by the dispersive forces between the pseudo-atoms and the oxygen atoms of the zeolite, ${ }^{28,35,44}$ meaning that the silicon van der Waals interactions

(50) Beerdsen, E.; Smit, B.; Calero, S. J. Phys. Chem. B 2002, 106, 1065910667.

(51) Beerdsen, E.; Dubbeldam, D.; Smit, B.; Vlugt, T. J. H.; Calero, S. J. Phys. Chem. B 2003, 107, 12088-12096.

(52) Kärger, J.; Vasenkov, S.; Auerbach, S. M. Diffusion in Zeolites. In Handbook of Zeolite Science and Technology; Auerbach, S. M., Carrado, K. A., Dutta, P. K., Eds.; Marcel Dekker: New York, 2003; pp 341-422. (53) Vlugt, T. J. H.; Schenk, M. J. Phys. Chem. B 2002, 106, 12757-12763.

(54) Ryckaert, J. P.; Bellemans, A. Faraday Discuss. Chem. Soc. 1978, 66, 95106. 
were taken into account through an effective potential with only the oxygen atoms.

In the force field described here an "average" polarization was included implicitly in the parametrization by means of two effects: the polarization induced by the cation on the zeolite and on the alkanes. For the cation-zeolite interactions, we used the approach of Auerbach, ${ }^{14}$ taking into account the polarization effects by adjusting the partial charges on the oxygen, depending whether they are connected to Si or Al. Concerning the polarization effects for the cation-alkane interactions, alkanes were very difficult to polarize, and therefore a logical approach was to use effective Lennard-Jones interactions between the cations and the alkanes.

B. Parameter Optimization. This work is concerned with a realistic description of the interaction between the sodium cations, the zeolite framework, and the alkanes. It turns out that the sodium cation distribution is a key factor to understand the adsorptive properties of the Na-FAU family of materials. However, diffraction methods are not always able to provide this information fully accurately. Even for wellstudied systems such as adsorbate-free $\mathrm{NaX}$ or $\mathrm{NaY}$ the precise location of some cations has remained uncertain. ${ }^{19,55,56}$ In marked contrast, there is general agreement on the sodium distribution in LTA-type zeolites. Especially, LTA-type zeolites with alternating silicon and aluminum atoms have a highly symmetrical ion distribution. The sodium form of such an LTA-type zeolite has 12 sodiums per supercage distributed among three crystallographic sites (see Figure 1a): in the center of the six ring (type 1), in the eight ring window (type 2), and opposite to a four ring (type 3). ${ }^{57}$ Crystallographic studies indicate that these sites are occupied for 97.2, 24.2, and 6.6\%, respectively. Molecular simulations with our optimized force field yield occupations of 100, 23.9 and $6.25 \%$, respectively. In addition, the crystallographic locations of the sites obtained through molecular simulations are within $0.2 \AA$ from those obtained though X-ray diffraction.

Using this set of parameters derived from this high alumina LTAtype zeolite, we performed simulations to obtain the average sodiumoxygen distances in FAU-type zeolite. The typical sites for sodium in adsorbate-free FAU-type zeolites are depicted schematically in Figure 1b. Sites I, I', and II' are in the sodalite cages and hexagonal prisms, while sites II, III, and III' are in the supercages. More specifically, site I is in the hexagonal prism, sites I' and II' are inside the sodalite cage, site II is located at the center of the hexagonal prisms but displaced from this point into the supercage, and site III is in the supercage on a twofold axis opposing a four ring between two 12 rings. Some studies report three additional supercage III' sites within $2.8 \AA$ of site III. The resulting sodium-oxygen distances are listed in Table 2. Although our results are within $0.2 \AA$ of the experiments, our distances are slightly larger than those reported experimentally. The scatter in the experimental data makes it difficult to assess whether this points to a systematic deviation.

The alkane-sodium, alkane-alkane, and alkane-zeolite interaction parameters were obtained by calibrating the force field through explicitly fitting a full isotherm over a wide range of pressures, temperatures, and sodium densities. We fit complete adsorption isotherms, because experimental determination of the adsorption properties at very low and at very high coverage is fraught with difficulty resulting in a large spread in experimentally determined Henry coefficients and saturation loadings, respectively. ${ }^{58,59}$ Experimental agreement on data in the intermediate coverage regime is significantly better. We started by obtaining a reduced set of reliable experimental data of several

(55) Mortier, W. J.; Bossche, E. V. d.; Uytterhoeven, J. B. Zeolites 1984, 4, 41-44.

(56) Fitch, A. N.; Jobic, H.; Renouprez, A. J. Phys. Chem. 1986, 90, 13111318.

(57) Pluth, J. J.; Smith, J. V. J. Am. Chem. Soc. 1980, 102, 4704-4708.

(58) Dubbeldam, D.; Calero, S.; Vlugt, T. J. H.; Krishna, R.; Maesen, T. L. M.; Beerdsen, E.; Smit, B. Phys. Rev. Lett. 2004, in press.

(59) Dubbeldam, D.; Calero, S.; Vlugt, T. J. H.; Krishna, R.; Maesen, T. L. M.; Smit, B. J. Phys. Chem. B 2004, in press. (a) LTA

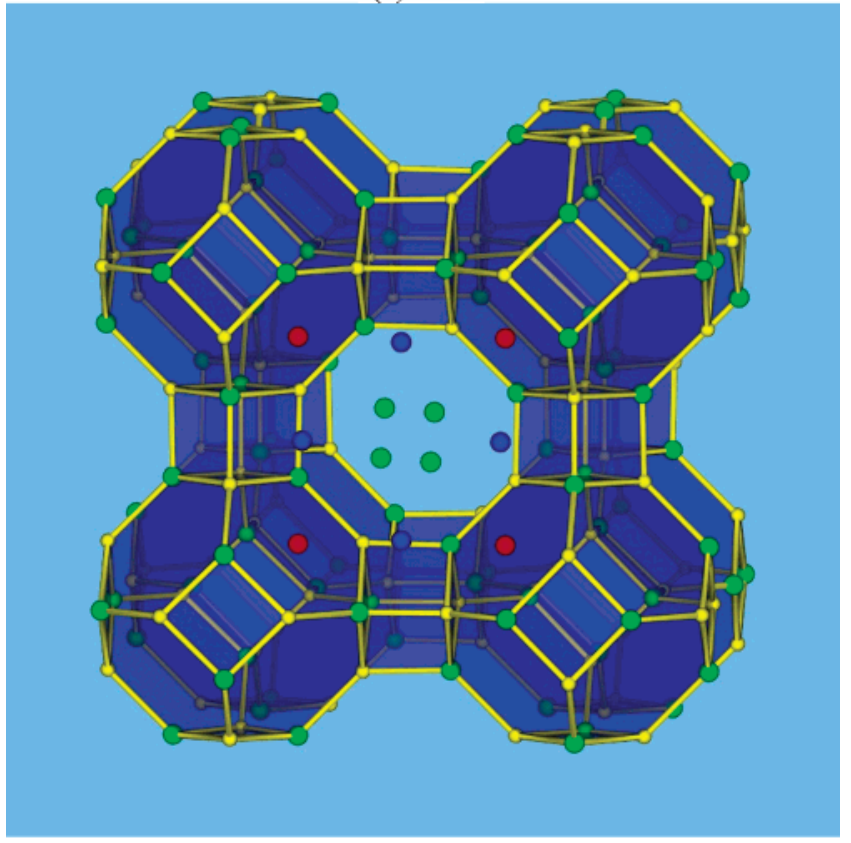

(b) FAU

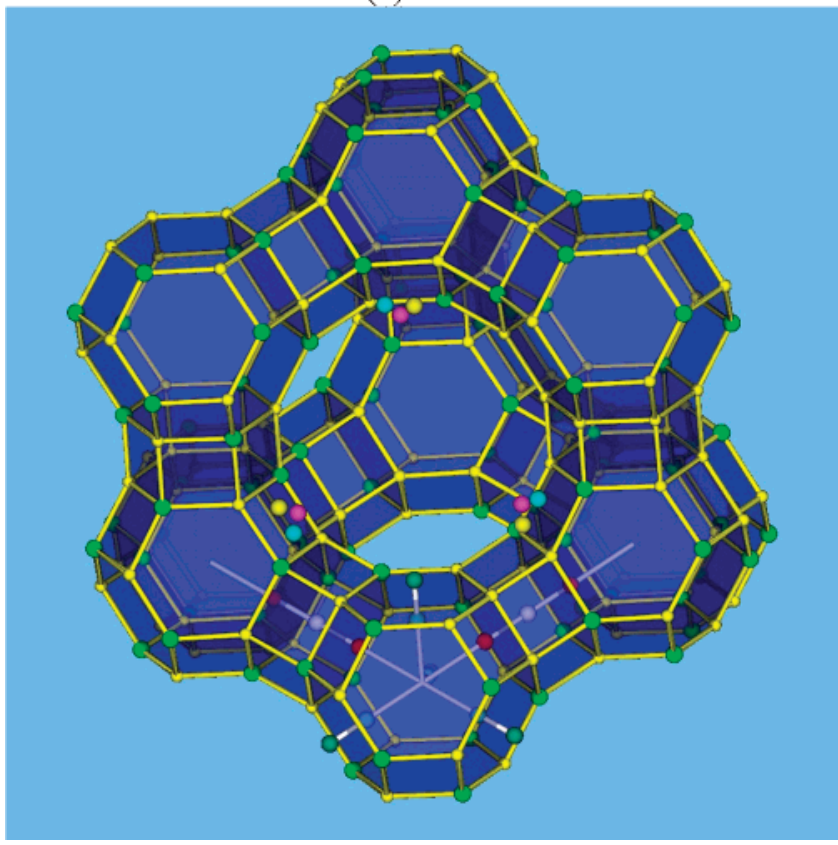

Figure 1. Positions of non-framework Na cations. (a) LTA-type zeolites. (b) FAU-type zeolites.

independent research groups, to calibrate the simulations results. Next we fit, starting with the smallest number of free parameters, and increased the number of parameters incrementally. Once a reasonable set of parameters was obtained, we reexamined the experimentally available data and included the data that were consistent with the original data set. This extended data set was subsequently used for further refinement of the parameters. The procedure was repeated to obtain a best fit with the majority of the experimental data. The resulting force field parameters are listed in Table 1. Except for $\mathrm{NaX}$, aluminum atoms were asymmetrically arranged in the simulation box. Thus, to compute a reliable quantity in the thermodynamic limit, we averaged over different aluminum atom arrangements in the simulation cell. Figure 2 shows the excellent agreement of our computed isotherms for methane, ethane, and propane with available experimental data..$^{29,60-70}$ Previous GCMC simulation data (only available for methane ${ }^{29,31}$ ) were 
Table 2. Sodium-Oxygen Distances $[\AA]$ in Faujasites

\begin{tabular}{|c|c|c|c|c|c|c|c|c|c|c|c|}
\hline & \multirow[b]{2}{*}{ this work } & \multicolumn{8}{|c|}{$\begin{array}{c}\text { other works } \\
\text { (experimental data) }\end{array}$} & \multicolumn{2}{|c|}{$\begin{array}{l}\text { other works } \\
\text { (simulations) }\end{array}$} \\
\hline & & ref 19 & ref 56 & ref 75 & ref 11 & ref 77 & ref 73 & ref 18 & ref 78 & ref 14 & ref 81 \\
\hline $\mathrm{Na}(\mathrm{I})-\mathrm{O}(3)$ & 2.53 & 2.74 & 2.71 & 2.71 & & 2.71 & & $2.3-2.4$ & 2.56 & $2.11-2.29$ & \\
\hline $\mathrm{Na}(\mathrm{I})-\mathrm{O}(2)$ & 3.53 & 3.55 & & & & & & & & & \\
\hline $\mathrm{Na}(\mathrm{I})-\mathrm{O}(1)$ & 3.74 & 3.82 & & & & & & & & & \\
\hline $\mathrm{Na}\left(\mathrm{I}^{\prime}\right)-\mathrm{O}(3)$ & 2.5 & $2.24-2.36$ & 2.24 & 2.32 & 2.24 & 2.44 & 2.27 & & 2.25 & $2.07-2.27$ & 2.14 \\
\hline $\mathrm{Na}\left(\mathrm{I}^{\prime}\right)-\mathrm{O}(2)$ & 3.11 & $2.94-2.97$ & & 2.97 & 2.9 & & 2.93 & & 3.08 & & \\
\hline $\mathrm{Na}(\mathrm{II})-\mathrm{O}(2)$ & 2.47 & 2.34 & 2.39 & 2.34 & 2.36 & 2.33 & 2.35 & & 2.34 & $2.15-2.36$ & 2.4 \\
\hline $\mathrm{Na}(\mathrm{II})-\mathrm{O}(4)$ & 3.06 & 2.89 & 2.86 & 2.89 & 2.9 & & 2.88 & & 3.1 & & \\
\hline $\mathrm{Na}\left(\mathrm{II}^{\prime}\right)-\mathrm{O}(2)$ & 2.52 & & & & & & & & & & \\
\hline $\mathrm{Na}\left(\mathrm{II}^{\prime}\right)-\mathrm{O}(4)$ & 3.31 & & & & & & & & & & \\
\hline $\mathrm{Na}\left(\mathrm{III} \mathrm{I}^{\prime} \mathrm{a}\right)-\mathrm{O}(4)$ & 2.64 & 2.22 & & & 2.77 & & & & 2.3 & 2.26 & 2.37 \\
\hline $\mathrm{Na}\left(\mathrm{III} \mathrm{I}^{\prime} \mathrm{a}\right)-\mathrm{O}(1)$ & 2.9 & 2.85 & & & 2.58 & & & & 2.87 & & \\
\hline $\mathrm{Na}\left(\mathrm{III} \mathrm{I}^{\prime} \mathrm{b}\right)-\mathrm{O}(4)$ & 2.5 & 2.58 & & & & & 2.56 & & & & \\
\hline $\mathrm{Na}\left(\mathrm{III}^{\prime} \mathrm{b}\right)-\mathrm{O}(1)$ & 2.74 & 2.61 & & & & & 2.44 & & & & \\
\hline $\mathrm{Na}\left(\mathrm{III}^{\prime} \mathrm{c}\right)-\mathrm{O}(4)$ & 2.51 & 2.41 & & & & & & & & & \\
\hline $\mathrm{Na}\left(\mathrm{III}^{\prime} \mathrm{c}\right)-\mathrm{O}(1)$ & 2.67 & 2.44 & & & & & & & & & \\
\hline
\end{tabular}

included for comparison. The number of sodium cations and the temperature used for each isotherm were chosen to facilitate comparison with the experimental data, in principle treated with equal weight, and simulations were performed in all pressure range. Hence, methane isotherms in Figure 2a were obtained for structures with 60 and 86 $\mathrm{Na}^{+}$at 298 and $330 \mathrm{~K}$, ethane isotherms; in Figure 2b, they were obtained for structures with 56 and $86 \mathrm{Na}^{+}$at $300 \mathrm{~K}$, and propane isotherms; in Figure 2c, they were obtained for structures with 58 and 86 at 300 and $293 \mathrm{~K}$, respectively. Figure 2c shows the experimental discrepancies of Dzhigit et al. ${ }^{66}$ and Hampson et al. ${ }^{67}$ with Palmas et al. ${ }^{68}$ These discrepancies are most likely due to factors such as structural imperfections, adsorption at the crystal surface, and pore-blocking that can render a large part of the zeolite inactive. The additional advantage of our simulations is to resolve these experimental discrepancies since they use "perfect" crystals and restrict the adsorption to the zeolite pores.

The resulting force field not only reproduces the experimental data from the calibration set, but also yields an extraordinarily good description of data not included in the calibration set. To validate the reliability of our force field, we computed adsorption isotherms of longer hydrocarbons (from $n$-butane to $n$-decane) and compared them with those available from experimental data. ${ }^{64,68,71,72} \mathrm{We}$ computed adsorption isotherms of alkanes at several temperatures in FAU-type zeolites with different $\mathrm{Na}^{+}$cation densities. It is noteworthy that our computed isotherms reproduced the experimental isotherm shape and also the experimental saturation capacity of the validation data set. As an example, Figure 3a shows the excellent agreement of the computed isotherm for butane compared to Thamm et al. ${ }^{71}$ at $300 \mathrm{~K}$ in Na-FAU

(60) Dunne, J. A.; Rao, M.; Sircar, S.; Gorte, R. J.; Myers, A. L. Langmuir 1996, 12, 5896-5904

(61) Barrer, R. M.; Sutherland, J. W. Proc. R. Soc. London, Ser. A 1956, 237, $439-463$.

(62) Talu, O.; Zhang, S. Y.; Hayhurst, D. T. J. Phys. Chem. 1993, 97, 1289412898.

(63) Chkhaidze, E. V.; Fomkin, A. A.; Serpinskii, V. V.; Tsitsishvili, G. V. Bull. Acad. Sci. USSR, Div. Chem. Sci. 1985, 34, 886-890.

(64) Tarek, M.; Kahn, R.; Delara, E. C. Zeolites 1995, 15, 67-72.

(65) Dzhigit, O. M.; Kiselev, A. V.; Rachmanova, T. A. J. Chem. Soc., Faraday Trans. 2 1979, 75, 2662-2677.

(66) Dzhigit, O. M.; Kiselev, A. V.; Rachmanova, T. A. Zeolites 1984, 4, 389397.

(67) Hampson, J. A.; Rees, L. V. C. In Zeolites and Microporous Crystals, Proceedings of the International Symposium on Zeolites and Microporous Crystals, Nagoya-shi, Japan, Aug 22-25, 1993; Hattori, T., Yashima, T. Eds.; Elsevier: Amsterdam, 1994; Vol. 83, pp 197-208.

(68) Palmas, S.; Polcaro, A. M.; Carta, R.; Tola, G. J. Chem. Eng. Data 1991 $36,1-4$.

(69) Stach, H.; Lohse, U.; Thamm, H.; Schirmer, W. Zeolites 1986, 6, 74-90.

(70) Zhang, S. Y.; Talu, O.; Hayhurst, D. T. J. Phys. Chem. 1991, 95, 17221726

(71) Thamm, H.; Stach, H.; Schirmer, W.; Fahlke, B. Z. Phys. Chem. (Leipzig) 1982, 263, 461-469.

(72) Janchen, J.; Stach, H. Zeolites 1985, 5, 57-59. with 82 sodium and aluminum atoms per unit cell. The agreement with experimental data of Tarek et al. ${ }^{64}$ in $\mathrm{NaX}$ with 86 sodium and aluminum per unit cell for butane $(300 \mathrm{~K})$ and pentane $(333 \mathrm{~K})$ is also remarkable (see Figure 3a,b), and it becomes outstanding in Figure 3c for decane in $\mathrm{NaX}$ with 83 sodium and aluminum atoms per unit cell at $413 \mathrm{~K}$.

The adsorption of alkanes is strongly determined by the sodium cations in faujasites. The effect of cations is twofold: (1) they create additional adsorption sites and (2) they occupy free volume. In cagelike structures the first effect dominates at low and intermediate loadings below the excluded volume effect. For a channel structure, the excluded volume effect is compensated for the adsorption effect at low loading. The effect of cations on FAU-type structures is therefore much larger than that for MFI.$^{50}$ We would like to highlight that both sodium density and sodium mobility are essential factors during adsorption of alkanes in faujasites. Figure 3 compares the adsorption isotherms for butane, pentane, and decane obtained using the new force field with isotherms in (a) FAU without cations and (b) FAU with a fixed cation distribution. The comparison between isotherms in the structures with and without cations shows that the pressure needed to reach a certain loading in the structure without cations is up to 3 orders of magnitude higher than the one needed in the structure with cations. The second comparison shows that mobility of cations is indispensable to reproduce adsorption of alkanes in sodium faujasites. Simulations using frozen cations overestimate the adsorption of alkanes at low pressures and underestimate the adsorption of alkanes at high pressures.

Having established that the force field reproduces the calibration and validation data sets extremely well, we can now show how this force field readily yields information on a molecular level that would be extremely cumbersome to obtain through experimental studies.

\section{Applications}

A. Cation Redistribution upon Alkane Adsorption. Low occupancies of cations at specific crystallographic locations tend to interfere with a complete determination of the cation distribution by crystallographic methods such as X-ray diffraction. Furthermore, very small amounts of adsorbates (particularly water) have a pronounced effect on the location of sodium cations. As a first application, our force field provides information about the cation redistribution upon alkane adsorption in the sodium forms of FAU-type zeolites. We used FAU-type zeolites with 96 and 58 sodium and aluminum atoms per unit cell (FAU-96 and FAU-58, respectively) at $300 \mathrm{~K}$. The study was carried out in two steps. First we performed simulations for the adsorbate-free zeolites to compare the force field for 
(a) Left NAY methane. Right NaX methane
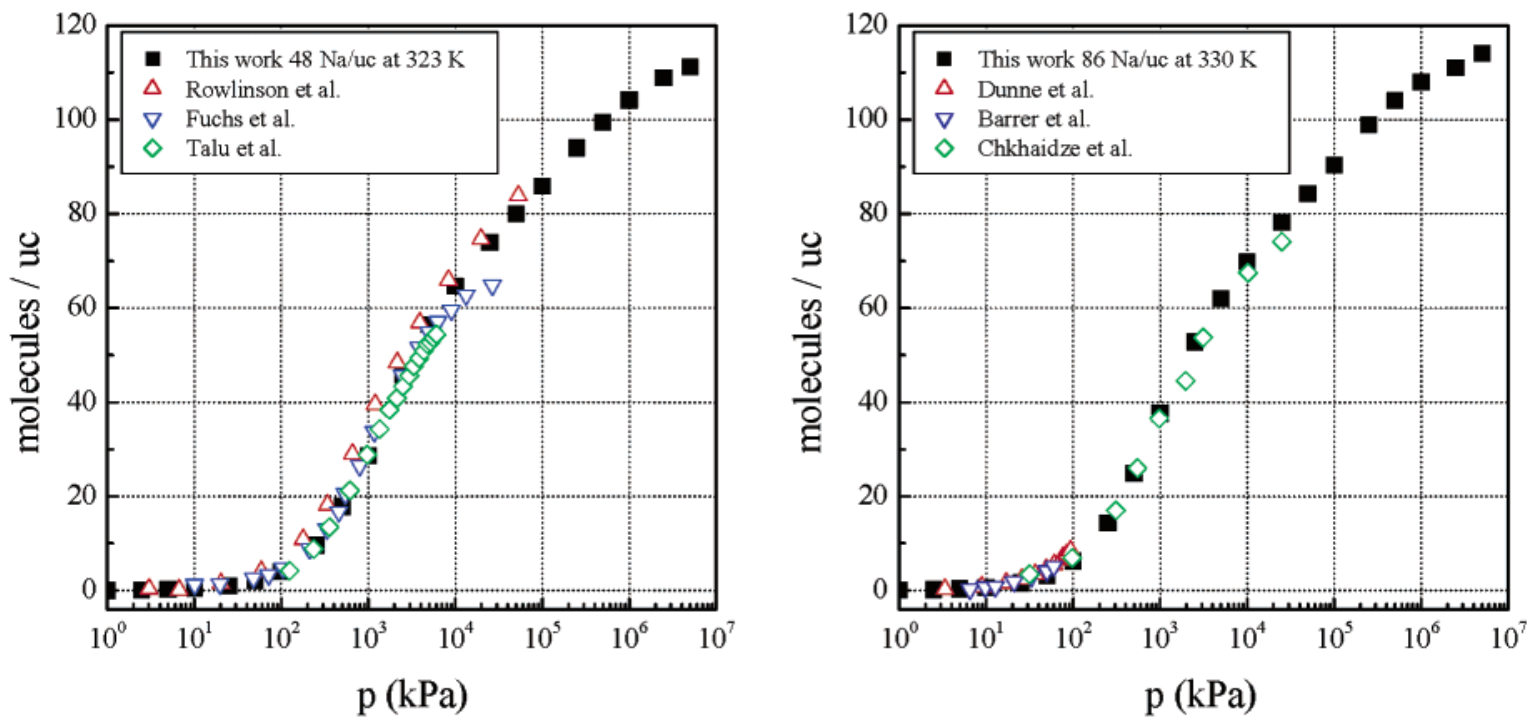

(b) Left NAY ethane. Right $\mathrm{NaX}$ ethane
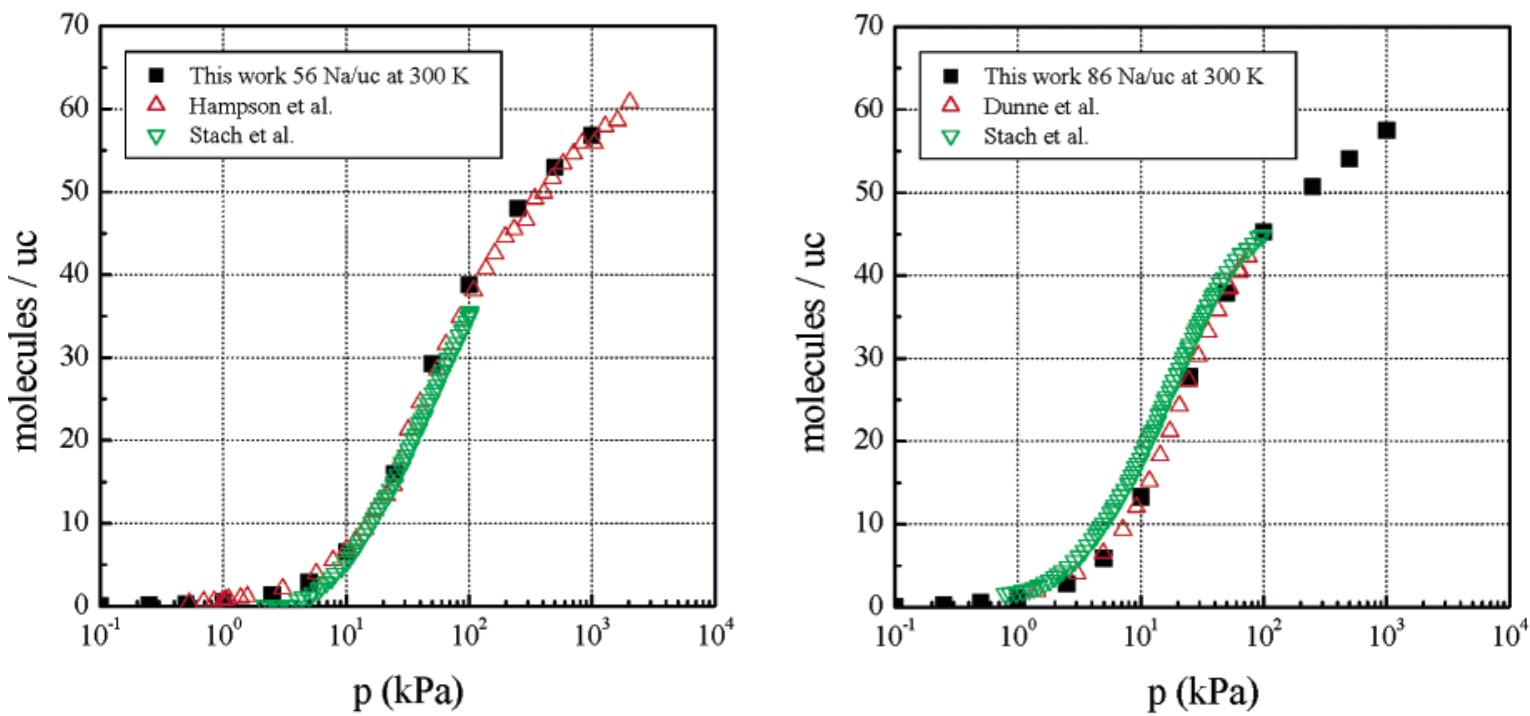

(c) Left $\mathrm{NaY}$ propane, Right $\mathrm{NaX}$ propane
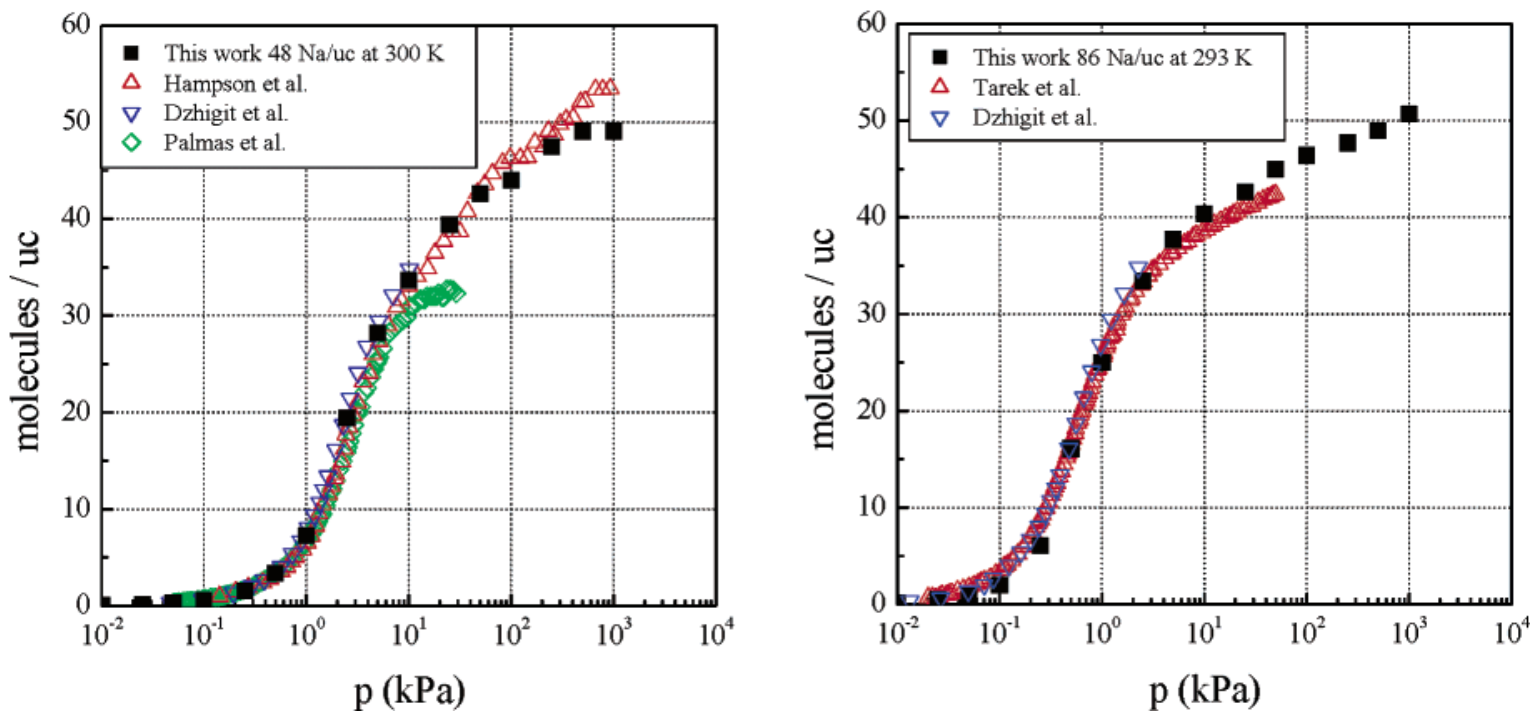

Figure 2. Adsorption isotherms of methane (a), ethane (b), and propane (c) in (left) NaY- and (right) NaX-type zeolites. Comparison with experimental data. $29,60-70$ 

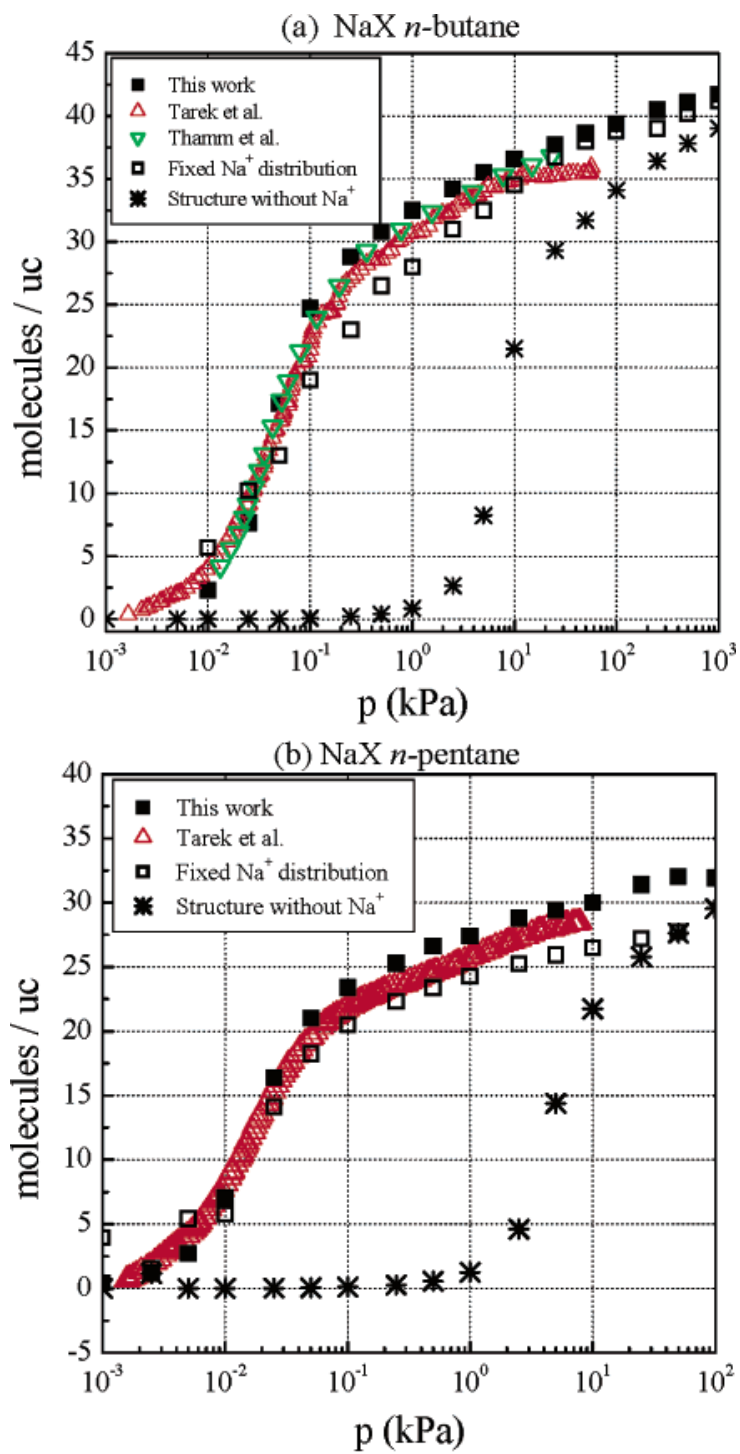

(c) $\mathrm{NaX} n$-decane

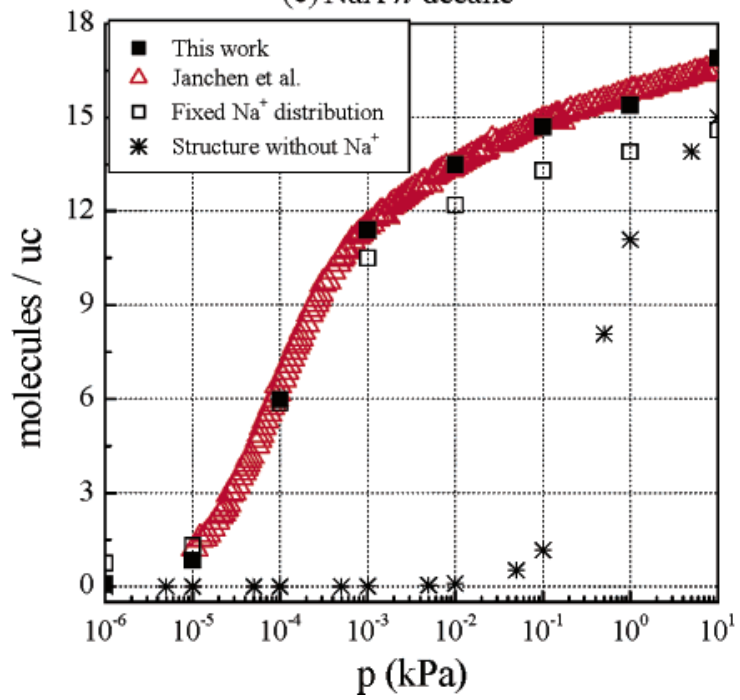

Figure 3. Adsorption isotherms in $\mathrm{NaX}$ zeolites with mobile cations, fixed cations, and without cations. (a) $n$-Butane at $300 \mathrm{~K}$, (b) $n$-pentane at 333 $\mathrm{K}$, and (c) $\mathrm{NaX} n$-decane at $413 \mathrm{~K}$. Comparison with experimental data. ${ }^{64,71,72}$

sodium with available experimental data, and subsequently we performed simulations with a loading up to 44 molecules of
Table 3. Sodium Cation Distributions (Sodium Cations per Site per Unit Cell) in Bare Sodium Faujasites at $10 \mathrm{~K}^{a}$

\begin{tabular}{|c|c|c|c|c|c|c|}
\hline $58 \mathrm{Na}^{+} / \mathrm{uc}$ & 1 & $\mathrm{I}^{\prime}$ & $\|$ & III'a & $\| l{ }^{\prime} b$ & $\| I I ' c$ \\
\hline this work & 7.3 & 15.7 & 31.6 & 3.4 & & \\
\hline Marra et al. ${ }^{76}$ & 9.3 & 13.7 & 25.3 & & 3.5 & \\
\hline Grey et al. ${ }^{75}$ & 4.3 & 18.9 & 32 & & & \\
\hline Lim and Grey ${ }^{74}$ & 3 & 17 & 30 & & & \\
\hline Van Dun et al. ${ }^{80}$ & 7.04 & 13.76 & 29.44 & & 3.76 & \\
\hline Boutin et al. ${ }^{81}$ & 6 & 20 & 32 & & & \\
\hline Fitch et al..$^{56}$ & 7.1 & 18.6 & 32.2 & & & \\
\hline Jirak et al. ${ }^{79}$ & 4 & 17.6 & 32 & & 1.4 & \\
\hline Newsam et al. ${ }^{78}$ & 10 & 12 & 32 & & 4 & \\
\hline Eulenberger et al. ${ }^{77}$ & 8 & 18.88 & 30.08 & & 0.04 & \\
\hline $96 \mathrm{Na}^{+} / \mathrm{uc}$ & I & $\mathrm{I}^{\prime}$ & $\|$ & III'a & $I I I^{\prime} b$ & $I I I \prime c$ \\
\hline this work & & 32 & 32 & 32 & & \\
\hline Cheetham et al. ${ }^{11}$ & & 32 & 32 & 32 & & \\
\hline Auerbach et al. ${ }^{14}$ & 3 & 29 & 32 & 27 & 5 & \\
\hline Boutin et al..$^{81}$ & & 32 & 32 & 31 & 1 & \\
\hline Olson $^{19}$ & 2.9 & 29.1 & 31 & 10.6 & 8.6 & 10.6 \\
\hline Zhu and Seff ${ }^{73}$ & & 29.5 & 35.2 & 18 & 10 & \\
\hline
\end{tabular}

${ }^{a}$ Previous simulation data used for comparison are shown in italics.

Table 4. Sodium Cation Distributions (Sodium Cations per Site per Unit Cell) in Butane-Loaded Sodium Faujasites at $300 \mathrm{~K}^{a}$

\begin{tabular}{|c|c|c|c|c|c|c|c|c|}
\hline \multicolumn{9}{|c|}{$58 \mathrm{Na}^{+} / \mathrm{uc}$} \\
\hline Butane loading & I & $l^{\prime}$ & $\|$ & $\mathrm{II}^{\prime}$ & III'a & III'b & $\| I^{\prime} \mathrm{C}$ & others \\
\hline 0 & 5.3 & 13.7 & 25.7 & 2.0 & 4.2 & 3.6 & 1 & 2.5 \\
\hline 0.6 & 5.0 & 5.8 & 17.8 & 5.1 & 13.3 & 4 & 1.7 & 5.3 \\
\hline 3 & 5.0 & 6.0 & 17.2 & 5.0 & 13.3 & 4 & 1.6 & 6 \\
\hline 27 & 5.0 & 6.0 & 17.4 & 5.0 & 12.5 & 4.8 & 1.8 & 5.5 \\
\hline 37 & 5.0 & 5.8 & 19.5 & 5.1 & 11.6 & 5.8 & 1.9 & 3.3 \\
\hline 42 & 5.0 & 6.0 & 18.3 & 5.0 & 12.2 & 4.8 & 2.7 & 4.0 \\
\hline 46 & 5.0 & 5.6 & 19.9 & 5.4 & 10.7 & 6.0 & 2.5 & 3.0 \\
\hline \multicolumn{9}{|c|}{$96 \mathrm{Na}^{+} / \mathrm{uc}$} \\
\hline Butane loading & 1 & $l^{\prime}$ & II & $\mathrm{II}^{\prime}$ & III'a & III'b & $I I^{\prime} \mathrm{C}$ & Others \\
\hline 0 & 4.2 & 24.8 & 32 & 0 & 33.4 & 0.9 & 0.7 & 0 \\
\hline 0.6 & 0.5 & 31.1 & 32 & 0 & 27 & 2.5 & 2.9 & 0 \\
\hline 3 & 0.9 & 30.8 & 32 & 0 & 26.5 & 2.8 & 3.0 & 0 \\
\hline 27 & 2.0 & 28.6 & 32 & 0 & 26.7 & 4.0 & 2.6 & 0 \\
\hline 37 & 1.8 & 28.5 & 32 & 0 & 26.6 & 2.3 & 2.8 & 0 \\
\hline 42 & 1.7 & 29.3 & 32 & 0 & 26.1 & 3.6 & 3.3 & 0 \\
\hline 46 & 1.0 & 30.5 & 32 & 0.1 & 23.7 & 5.6 & 3.0 & 0.2 \\
\hline
\end{tabular}

${ }^{a}$ The loading of butane is given in molecules per unit cell.

butane per unit cell, i.e., up to approximately the butane saturation loading (loading obtained at $1000 \mathrm{kPa}$ ).

The sodium cation occupancies obtained from our simulations for the adsorbate-free FAU-type zeolites are fully consistent with the available experimental ${ }^{11,19,56,73-80}$ and simulation data ${ }^{14,81}$ as shown in Table 3. For FAU-96, the simulation results are in excellent agreement with experiment, and cations occupy predominantly sites I', II, and III'a. For FAU-58, simulations locate the sodium cations at sites I', I, and II. Within experimental error, the match between simulations and experiments is again remarkable. These results further corroborate our force field. Subsequently, butane adsorption was simulated (Table 4).

(73) Zhu, L.; Seff, K. J. Phys. Chem. B 1999, 103, 9512-9518.

(74) Lim, K. H.; Grey, C. P. J. Am. Chem. Soc. 2000, 122, 9768-9780.

(75) Grey, C. P.; Poshni, F. I.; Gualtieri, A. F.; Norby, P.; Hanson, J. C.; Corbin D. R. J. Am. Chem. Soc. 1997, 119, 1981-1989.

(76) Marra, G. L.; Fitch, A. N.; Zecchina, A.; Ricchiardi, G.; Salvalaggio, M. Bordiga, S.; Lamberti, C. J. Phys. Chem. B 1997, 101, 10653-10660.

(77) Eulenberger, G. R.; Shoemaker, D. P.; Keil, J. G. J. Phys. Chem. 1967, $71,1812-1819$

(78) Newsam, J. M.; Jacobson, A. J.; Vaughan, E. W. J. Phys. Chem. 1986, 90 , $6858-6864$.

(79) Jirak, Z.; Vratislav, S.; Bosacek, V. J. Phys. Chem. Solids 1980, 41, 10891095.

(80) Vandun, J. J.; Dhaeze, K.; Mortier, W. J. J. Phys. Chem. 1988, 92, 67476754

(81) Buttefey, S.; Boutin, A.; Mellot-Draznieks, C.; Fuchs, A. H. J. Phys. Chem. B 2001, 105, 9569-9575. 
Table 5. Heats of Adsorption of $n$-Alkanes in Sodium Faujasites ${ }^{a}$

\begin{tabular}{|c|c|c|c|c|c|c|c|c|}
\hline & \multicolumn{2}{|c|}{ Methane } & \multicolumn{2}{|c|}{ Ethane } & \multicolumn{2}{|c|}{ Propane } & \multicolumn{2}{|c|}{ Butane } \\
\hline $\mathrm{Na}^{+} / \mathrm{uc}$ & this work & others & this work & others & this work & others & this work & others \\
\hline 0 & 12.2 & $14.0^{89}$ & 16.6 & - & 21.1 & - & 25.6 & - \\
\hline 14 & 12.7 & - & 17.8 & - & 23.7 & $28.1^{66}$ & 27.9 & - \\
\hline 48 & 14.1 & $\begin{array}{l}17.8^{31} \\
15.5^{32}\end{array}$ & 20.6 & - & 27.0 & - & 34.2 & $22.5^{40}$ \\
\hline 52 & 14.3 & $15.2^{82}$ & 20.8 & $21.3^{82}$ & 27.3 & $27.3^{82}$ & 33.8 & $33.4^{82}$ \\
\hline 54 & 14.3 & - & 21.1 & $26.4^{69}$ & 28.3 & $31.3^{66}$ & 35.2 & $41.4^{71}$ \\
\hline 56 & 14.4 & - & 21.4 & $23.6^{90}$ & 28.5 & $29.6^{90}$ & 34.5 & - \\
\hline 57 & 14.5 & - & 21.3 & - & 28.6 & $28.5^{66}$ & 34.8 & - \\
\hline 60 & 14.6 & $18.9^{62}$ & 21.5 & - & 28.5 & - & 35.0 & - \\
\hline 76 & 15.2 & - & 22.9 & - & 30.2 & $35.0^{66}$ & 35.5 & - \\
\hline 82 & 15.5 & $18.8^{61}$ & 28.4 & $25.9^{61}$ & 31.2 & - & 39.1 & $46.1^{71}$ \\
\hline 83 & 15.6 & $\begin{array}{l}20.1^{70} \\
15.2^{28}\end{array}$ & 23.4 & - & 31.4 & - & 39.3 & - \\
\hline \multirow[t]{2}{*}{86} & 15.7 & $\begin{array}{l}19.2^{60} \\
17.6^{91}\end{array}$ & 23.6 & $\begin{array}{l}27.0^{60} \\
25.1^{91}\end{array}$ & $\begin{array}{l}31.4 \\
31.5\end{array}$ & $\begin{array}{l}32.4^{64} \\
31.0^{66}\end{array}$ & 39.3 & $39.1^{64}$ \\
\hline & \multicolumn{2}{|c|}{ Pentane } & \multicolumn{2}{|c|}{ Hexane } & \multicolumn{2}{|c|}{ Heptane } & \multicolumn{2}{|c|}{ Octane } \\
\hline $\mathrm{Na}^{+} / \mathrm{uc}$ & this work & others & this work & others & this work & others & this work & others \\
\hline 48 & 41.0 & $28.9^{40}$ & 47.8 & $34.8^{40}$ & 54.6 & $40.4^{40}$ & 61.4 & $45.2^{40}$ \\
\hline $\begin{array}{l}40 \\
52\end{array}$ & 40.3 & $39.4^{82}$ & 46.8 & $45.5^{82}$ & 53.0 & $51.9^{82}$ & 59.8 & $57.5^{82}$ \\
\hline 57 & 41.9 & - & 50.1 & $56.0^{92}$ & 55.6 & - & 62.4 & - \\
\hline \multirow[t]{2}{*}{86} & 47.2 & $46.6^{64}$ & 55.1 & $\begin{array}{l}54.1^{64} \\
56.0^{93}\end{array}$ & 62.9 & $\begin{array}{l}61.6^{64} \\
63.594\end{array}$ & 72.0 & - \\
\hline & \multicolumn{2}{|c|}{ Nonane } & \multicolumn{2}{|c|}{ Decane } & \multicolumn{2}{|c|}{ Undecane } & \multicolumn{2}{|c|}{ Dodecane } \\
\hline $\mathrm{Na}^{+} / \mathrm{uc}$ & this work & others & this work & others & this work & others & this work & others \\
\hline 32 & 60.0 & - & 67.1 & $74.0^{72}$ & 71.6 & - & 77.5 & - \\
\hline 48 & 68.1 & $56.1^{40}$ & 72.4 & & 78.9 & - & 85.4 & - \\
\hline 52 & 66.3 & $63.4^{82}$ & 72.8 & $70.8^{82}$ & 79.3 & $77.4^{82}$ & 85.8 & $81.7^{82}$ \\
\hline 57 & 69.3 & - & 78.4 & $81.6^{72}$ & 83.0 & - & 89.8 & - \\
\hline 83 & 78.9 & - & 89.3 & $91.9^{72}$ & 94.7 & - & 102.6 & - \\
\hline
\end{tabular}

${ }^{a}$ The heats of adsorption are obtained using our empirical expression at the temperatures referred to in the experimental works that we use for comparison. When available, previous simulation data are also included in italics. For the values without comparison, the temperature used is $503 \mathrm{~K}$, and in all cases heats of adsorption are given in $\mathrm{kJ} / \mathrm{mol}$.

The adsorption of butane clearly redistributes the sodium cations. In FAU-58, butane adsorption enhances the population of sites II' and III and delocalized sites in the supercage at the cost of sites I' and II. In FAU-96, butane adsorption induces a smaller sodium migration from site I' to sites I and III'. Furthermore, butane adsorption counteracts the migration of sodium from site $\mathrm{I}^{\prime}$ to the supercage as a result of an increase in temperature.

B. Adsorption in Low-Coverage Regime. Henry coefficients and heats of adsorption of linear alkanes were computed for a wide range of temperatures and the full range of aluminum (and sodium) densities. The obtained values were fitted to an empirical expression that describes the $n$-alkane Henry coefficient $K_{\mathrm{H}}\left[\mathrm{mol} \mathrm{kg}^{-1} \mathrm{~Pa}^{-1}\right]$ as a function of sodium density Ns [cations per unit cell], the temperature $T[\mathrm{~K}]$, and the carbon number $\mathrm{CN}$.

$$
\begin{array}{r}
\ln K_{\mathrm{H}}=\frac{1}{T^{2}}[(144.1 \mathrm{Ns}+27438.4) \mathrm{CN}-49567.3]+ \\
\frac{1}{T}[(4.37 \mathrm{Ns}+432.8) \mathrm{CN}+1111.13]-(0.00135 \mathrm{Ns}+ \\
0.3716) \mathrm{CN}-17.634(1)
\end{array}
$$

The temperature derivative of this equation provides an expression for the adsorption enthalpy $\Delta H_{0}(\mathrm{~kJ} / \mathrm{mol})$ :

$$
\begin{aligned}
-\Delta H_{0}=\frac{2}{T}[(144.1 \mathrm{Ns}+ & 27438.4) \mathrm{CN}-49567.3]+ \\
& (4.37 \mathrm{Ns}+432.8) \mathrm{CN}+1111.13
\end{aligned}
$$

Figure 4 compares the Henry coefficients obtained for $n$-alkanes from this empirical expression with available experimental data. ${ }^{64-68,82}$ The calculated heats of adsorption of methane to dodecane in faujasite structures are given in Table 5. Comparison with the large experimental data set available is

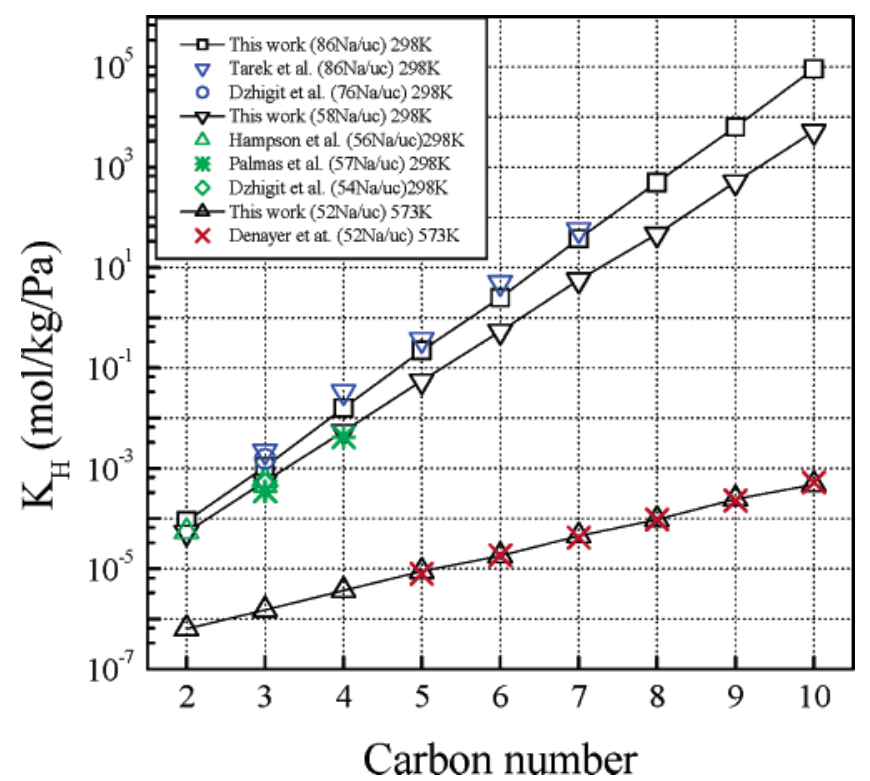

Figure 4. Henry coefficients of linear alkanes in sodium faujasites at several temperatures obtained from our empirical expression. In all cases, deviation between our empirical (eq 1) and computed results is smaller than the symbol size. Available experimental and simulation sets are included for comparison. ${ }^{64-66,68,82,90}$

also included in the table and shown as a function of the carbon number in Figure 5, parts a and b, respectively. It is noteworthy that these data were not part of the calibration of validation data. The remarkable quantitative agreement and consistency on low-coverage properties of simulated and experimental data thus further corroborates and validates the new force field.

C. Adsorption in High-Coverage Regime. The applicability of the force field is by no means limited to low pressure, for it also reproduces accurately the adsorption of alkanes at high pres- 


\section{(a) $\mathrm{NaY}$}

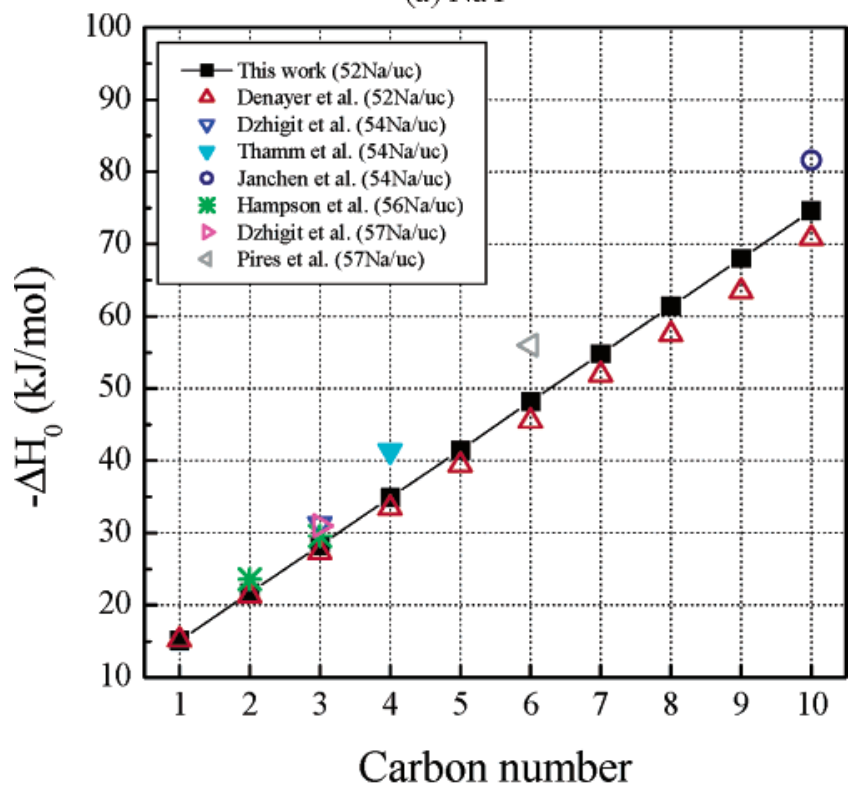

(b) $\mathrm{NaX}$

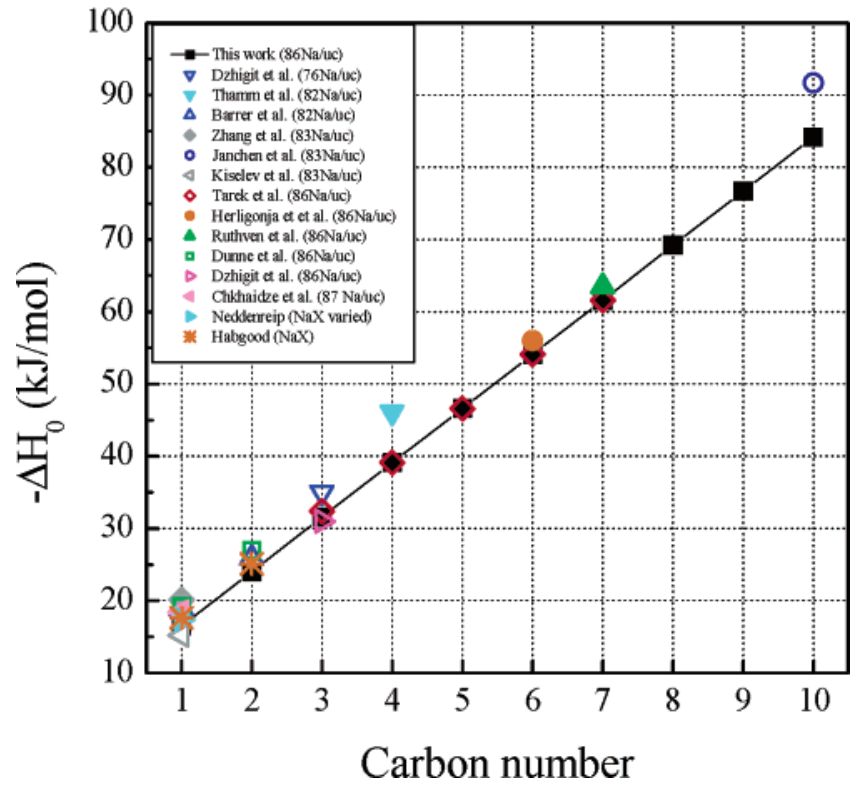

Figure 5. Heats of adsorption of linear alkanes in sodium faujasites obtained from our empirical expression. (a) $\mathrm{NaY}$ zeolites. (b) $\mathrm{NaX}$ zeolites. In all cases, deviation between our empirical (eq 2) and computed results is smaller than the symbol size. Available experimental and simulation sets are included for comparison. ${ }^{35,61,63-66,68,70-72,82,90-96}$

sures. The saturation capacities of $n$-alkanes (methane to hexadecane) were computed for several $\mathrm{Na}$ faujasites structures. From our simulations we can conclude that (1) saturation capacities $\theta_{\text {sat }}$ [molecules per unit cell] are roughly independent of the amount of sodium non-framework cations and (2) they can be fit to a second-order exponential decay as a function of the carbon number $(\mathrm{CN})$ :

$\theta_{\text {sat }}[$ molecules $/ \mathrm{uc}]=2.6+144.9 \exp -\left[\frac{\mathrm{CN}}{1.7}\right]+50.6 \exp -\left[\frac{\mathrm{CN}}{9.3}\right]$

$\theta_{\text {sat }}[$ molecules $/ \mathrm{uc}]=\theta_{\text {sat }}\left[\mathrm{mol} \cdot \mathrm{kg}^{-1}\right] \cdot N_{\mathrm{AV}} \cdot \rho\left[\mathrm{kg} \cdot \mathrm{m}^{-3}\right] \cdot V\left[\mathrm{~m}^{3}\right]$

where $N_{\mathrm{Av}}$ is Avogadro's number, $\rho$ is the zeolite density, and $V$ is the volume of the unit cell. The saturation capacity [mol

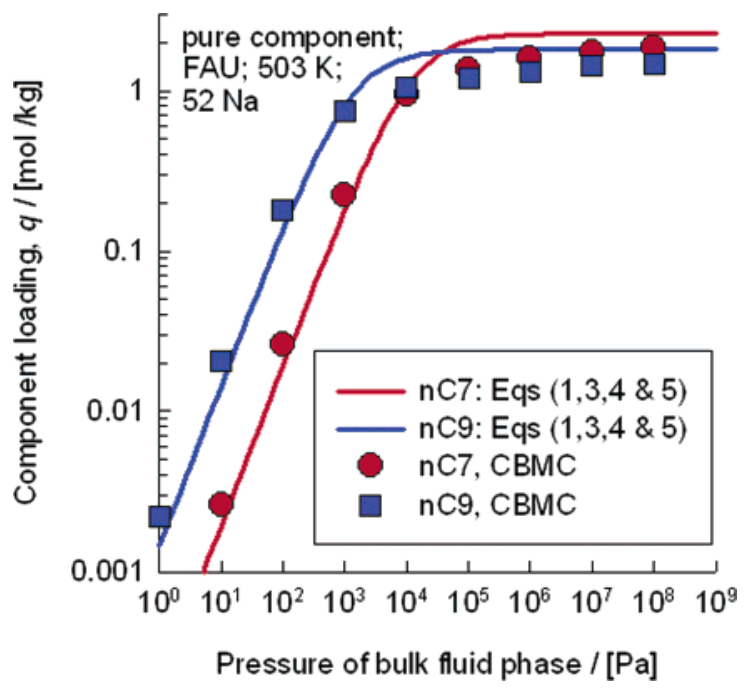

Figure 6. Adsorption isotherms of $n$-heptane and $n$-nonane in sodium faujasites using (1) CBMC simulation (symbols) and (2) a Langmuir model in which the parameters are calculated from eqs $1,3,4$, and 5 (line).

$\mathrm{kg}^{-1}$ ], along with the expression for the Henry coefficients (eq 1), allows the direct estimation of the adsorption isotherms of linear alkanes in sodium faujasites. The above correlations for the Henry coefficient and the saturation capacity can be used to obtain rough estimate of the complete adsorption isotherm, by using the Langmuir isotherm in the form:

$$
\theta=\frac{K_{\mathrm{H}} \mathrm{p}}{1+\left(K_{\mathrm{H}} / \theta_{\text {sat }}\right) \mathrm{p}}
$$

where $\theta$ is the loading of alkane in the zeolite in mole per kilogram and $\mathrm{p}$ is the system pressure in $\mathrm{Pa}$. Calculations using the above expression are in good agreement with the adsorption isotherms obtained from CBMC. This can be observed in Figure 6 for the adsorption of $n$-C7 and $n$-C9 in FAU containing 52 sodium cations.

D. Simultaneous Adsorption of More Than One Component. Of particular interest for the catalytic use of zeolites is the adsorption selectivity from mixtures of alkanes. In zeolites with extremely large pores one would expect that the alkane with the highest boiling point adsorbs preferentially. Remarkably, LTA-, ${ }^{83}$ FAU-, ${ }^{84}$ MFI-,${ }^{85}$ and BEA-type zeolites ${ }^{86}$ occasionally prefer absorbing the $n$-alkane with the lower boiling point, because it has a higher packing efficiency (i.e., a lower adsorption entropy) than the longer $n$-alkane with a higher boiling point. ${ }^{9,84}$ Experimental reproduction of the initially reported entropic preference of $\mathrm{NaY}$ for $n$-octane instead of $n$-decane, $n$-dodecane, or $n$-tetradecane proved difficult ${ }^{87}$ despite indications that adequate measures were taken to minimize intrusion from variations in sample preparation. ${ }^{88}$ Recent experiments established that $\mathrm{NaY}$ does prefer adsorbing the shorter, lower boiling alkane from a mixture $n$-heptane and $n$-nonane at high pressure. Simulations using the best force field available at the time ${ }^{50}$ corroborate the experiments in that they show a change in preference from $n$-heptane to $n$-nonane at

(82) Denayer, J. F. M.; Baron, G. V. Adsorption 1997, 3, 251-265.

(83) Sundstrom, D. W.; Krautz, F. G. J. Chem. Eng. Data 1968, 13, 223-226.

(84) Satterfield, C. N.; Smeets, J. K. AICHe J. 1974, 20, 618-619.

(85) Denayer, J. F. M.; De Meyer, K.; Martens, J. A.; Baron, G. V. Angew. Chem., Int. Ed. 2003, 42, 2774-2777.

(86) Denayer, J. F.; Ocakoglu, A. R.; De Jonckheere, B. A.; Martens, J. A Thybaut, J. W.; Marin, G. B.; Baron, G. V. Int. J. Chem. React. Eng. 2003, $1, \mathrm{~A} 36$. 
Table 6. Simulated and Experimenta| ${ }^{88}$ Liquid Phase Adsorption from a Mixture of $n$-Octane, $n$-Decane, $n$-Dodecane, and $n$-Tetradecane, Respectivelya

\begin{tabular}{|c|c|c|c|c|c|c|c|}
\hline \multicolumn{2}{|c|}{ pressure $(\mathrm{kPa})$} & \multicolumn{2}{|c|}{$\begin{array}{l}\text { molecules adsorbed/uc } \\
\text { (simulations) }\end{array}$} & \multicolumn{2}{|c|}{$\begin{array}{l}\text { molar fractions for } \mathrm{C} 8 \\
\quad \text { (simulations) }\end{array}$} & \multicolumn{2}{|c|}{$K=X_{C 8^{a}}\left(1-X_{C 8^{g}}\right) / X_{C 8^{g}}\left(1-X_{C 8}{ }^{a}\right)$} \\
\hline $\mathrm{p}_{\mathrm{C} 8}$ & $\mathrm{p}_{\mathrm{C} 10}$ & $\mathrm{n}_{\mathrm{C} 8}$ & $\mathrm{n}_{\mathrm{C} 10}$ & $\mathrm{X}_{\mathrm{C} 8^{g}}$ & $\mathrm{X}_{\mathrm{C} 8}{ }^{a}$ & $K_{\text {Simulation }}$ & $K_{\text {Satterfield }}$ \\
\hline 7.46 & 93.86 & 0.096 & 18.287 & 0.074 & 0.0052 & 0.07 & 2.00 \\
\hline 7365 & 92635 & 0.297 & 19.411 & 0.074 & 0.0151 & 0.19 & \\
\hline $\mathrm{p}_{\mathrm{C} 8}$ & $\mathrm{p}_{\mathrm{C} 12}$ & $\mathrm{n}_{\mathrm{C} 8}$ & $\mathrm{n}_{\mathrm{C} 12}$ & $\mathrm{X}_{\mathrm{C}^{g}}{ }^{g}$ & $\mathrm{X}_{\mathrm{C} 8^{a}}$ & $K_{\text {Simulation }}$ & $K_{\text {Satterfield }}$ \\
\hline 8.81 & 92.52 & 0.069 & 16.556 & 0.087 & 0.0042 & 0.04 & 1.7 \\
\hline 8690.93 & 91309.07 & 0.564 & 16.432 & 0.087 & 0.0332 & 0.36 & \\
\hline $\mathrm{p}_{\mathrm{C} 8}$ & $\mathrm{p}_{\mathrm{C} 14}$ & $\mathrm{n}_{\mathrm{C} 8}$ & $\mathrm{n}_{\mathrm{C} 14}$ & $\mathrm{X}_{\mathrm{C}^{g}}{ }^{g}$ & $\mathrm{X}_{\mathrm{C} 8}{ }^{a}$ & $K_{\text {Simulation }}$ & $K_{\text {Satterfield }}$ \\
\hline 10.11 & 91.21 & 1.983 & 13.298 & 0.100 & 0.1298 & 1.35 & 2.9 \\
\hline 9979.43 & 90020.57 & 2.563 & 12.372 & 0.100 & 0.1716 & 1.87 & \\
\hline
\end{tabular}

${ }^{a}$ In agreement with recent experiments, ${ }^{87}$ the simulations only qualitatively reproduce the preference for the shorter $n$-octane over the longer $n$-alkane for $n$-octane $/ n$-tetradecane mixtures.

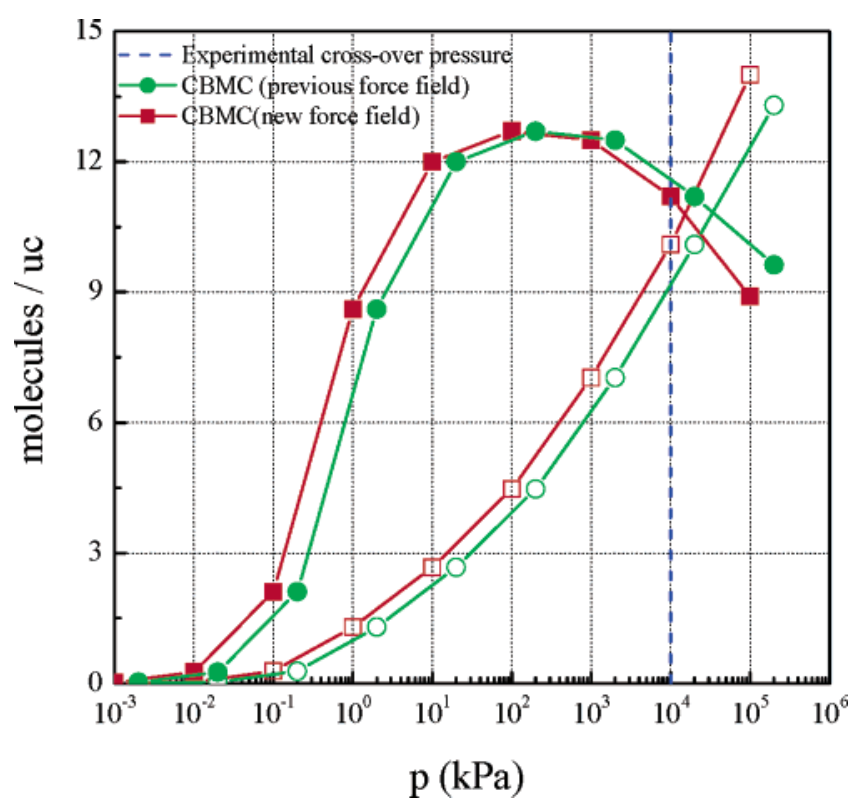

Figure 7. Adsorption isotherms of an equimolar mixture of $n$-nonane (open symbols) and $n$-heptane (closed symbols) mixture obtained with CBMC simulations using (1) the previous available force field ${ }^{50}$ (green circles) and (2) our new developed force field (red squares). The experimentally predicted crossover pressure is also included for comparison (blue line).

sufficiently high pressure. ${ }^{9}$ However, the crossover pressure is significantly higher than that observed experimentally. In marked contrast, by repeating the simulations with the force field for sodium discussed in the current article we found that the crossover pressure yields nearly quantitative agreement (Figure 7). This is notable, for it illustrates the successful application of the force field to systems very different from the calibration data. In agreement with recent experiments, the force field does

(87) Denayer, J. F.; Bouyermaouen, A.; Baron, G. V. Ind. Eng. Chem. Res. 1998, 37, 3691-3698.

(88) Satterfield, C. N.; Hayhurst, D. T. AICHe J. 1974, 20, 1023-1024.

(89) Yang, L.; Trafford, K.; Kresnawahjuesa, O.; Sepa, J.; Gorte, R. J.; White, D. J. Phys. Chem. B 2001, 105, 1935-1942.

(90) Hampson, J. A.; Rees, L. V. C. J. Chem. Soc., Faraday Trans. 1993, 89, 3169-3176.

(91) Habgood, H. W. Can. J. Chem. 1964, 42, 2340-2350.

(92) Pires, J.; Decarvalho, M. B.; Ribeiro, F. R.; Derouane, E. Appl. Catal. 1989 53, 273-277.

(93) Hercigonja, R. V.; Radak, V. M.; Gal, I. J. Zeolites 1992, 12, 54-55.

(94) Ruthven, D. M.; Doetch, I. H. AICHe J. 1976, 22, 882-886.

(95) Dunne, J. A.; Mariwals, R.; Rao, M.; Sircar, S.; Gorte, R. J.; Myers, A. L. Langmuir 1996, 12, 5888-5895.

(96) Neddenreip, R. J. J. Colloid Interface Sci. 1968, 28, 293-304. not reproduce the preference of $\mathrm{NaY}$ for $n$-octane instead of $n$-decane or $n$-dodecane reported in the 1970s (Table 6). It does, qualitatively, corroborate a preference for adsorbing $n$-octane instead of $n$-tetradecane (Table 6). Without further experimental work it is difficult to fathom why the first report on adsorption entropy effects with FAU-type zeolites is not fully consistent with present-day research.

\section{Conclusions}

We have developed and validated a united atom force field for alkanes in the sodium form of FAU-type zeolites that explicitly distinguishes $\mathrm{Si}$ and $\mathrm{Al}$ atoms through the different type of framework oxygen atoms and that accounts for the density, mobility, and interactions with the adsorbate of the nonframework cation. The force field reproduces accurately the sodium positions in dehydrated FAU-type zeolites known from crystallography and the available experimental adsorption properties of $n$-alkanes in faujasites over a wide range of sodium cation densities, temperatures, and pressures.

The applicability of this force field is manifold since it has been fitted in such a way that it is not limited to low pressure and pure adsorbents, for it also successfully reproduces the adsorption of binary mixtures at high pressure. First, the force field is suitable to predict sodium cation redistribution when $n$-alkanes adsorb, showing that cations in the sodalite cages are significantly more sensitive to the $n$-alkane loading than those in the supercages. Second, the force field is also suitable to predict adsorption properties in the low-pressure regime. From the resulting simulation data, we have obtained a simple empirical expression that describes the $n$-alkane Henry coefficient and adsorption enthalpy as a function of sodium density and temperature at low coverage, affording an adequate substitute for complex configurational-bias Monte Carlo simulations.

Acknowledgment. We would like to thank the Netherlands Research Council for Chemical Sciences, the European Commission for a Marie Curie Individual Research Fellowship to S.C., and Chevron Texaco for financial support. J.F.M.D. is grateful to the F.W.O-Vlaanderen for a fellowship as postdoctoral researcher. J.A.M. acknowledges the Flemish Government for a concerted research action on the understanding of the elementary active site in catalysis.

JA0476056 